\title{
Characteristics and distribution of microplastics in the coastal mangrove sediments of China
}

\author{
Qian Zhou ${ }^{\mathrm{a}, \mathrm{c}, \mathrm{e}}$, Chen Tu ${ }^{\mathrm{a}}$, Chuancheng Fu ${ }^{\mathrm{a}, \mathrm{b}}$, Yuan $\mathrm{Li}^{\mathrm{a}}$, Haibo Zhang ${ }^{\mathrm{d}}$, Kuanxu Xiong ${ }^{\mathrm{a}}$, Xinyue Zhao ${ }^{\mathrm{a}}$, \\ Lianzhen $\mathrm{Li}^{\mathrm{a}}$, Joanna J. Waniek ${ }^{\mathrm{e}}$, Yongming Luo ${ }^{\mathrm{a}, \mathrm{b}, \mathrm{c}, *}$

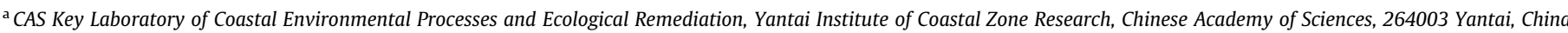 \\ ${ }^{\mathrm{b}}$ CAS Key Laboratory of Soil Environment and Pollution Remediation, Institute of Soil Science, Chinese Academy of Sciences, 210008 Nanjing, China \\ 'College of Resources and Environment, University of Chinese Academy of Sciences, 100049 Beijing, China \\ ${ }^{\mathrm{d}}$ Key Laboratory of Soil Contamination Bioremediation of Zhejiang Province, School of Environmental E Resource Sciences, Zhejiang Agriculture and Forestry University, \\ 311300 Hangzhou, China \\ e Leibniz Institute for Baltic Sea Research, 18119 Rostock, Germany
}

\section{H I G H L I G H T S}

- First comprehensive study on MPs in mangrove sediments along the coast of China.

- The MPs abundance in mangrove sediments was up to 8.5 times higher than in mangrove free sediments.

- The sandy sediments were dominated by foams, and the muddy sediments by fibers and fragments.

\section{A R T I C L E I N F O}

\section{Article history:}

Received 13 August 2019

Received in revised form 2 October 2019

Accepted 2 October 2019

Available online 31 October 2019

Editor: Damia Barcelo

\section{Keywords:}

Microplastics

Mangrove sediments

Surface morphologies

Abundance

Spatial distribution
G R A P H I C A L A B S T R A C T

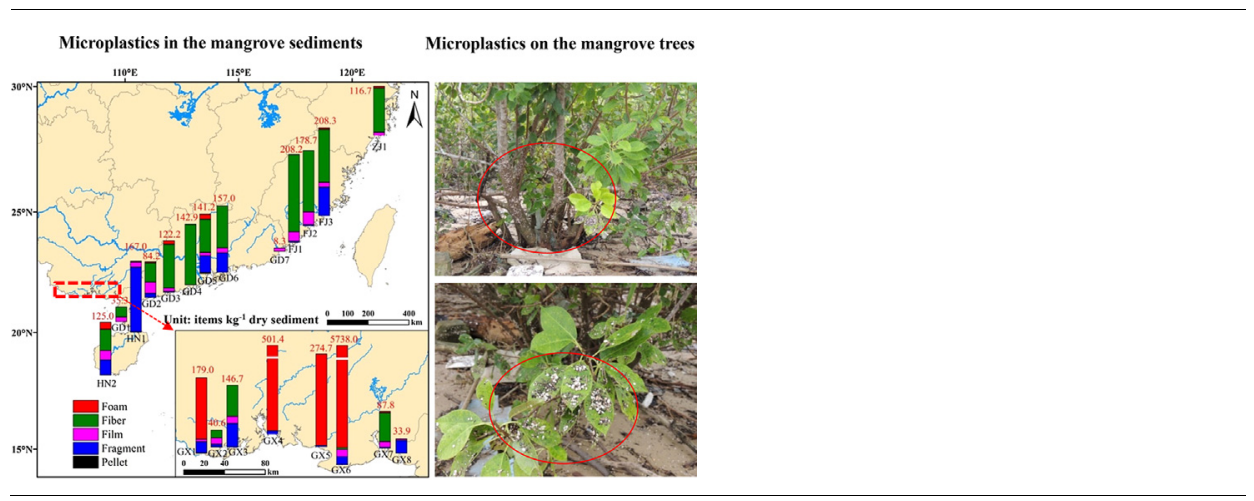

\begin{abstract}
A B S T R A C T
Mangroves are a unique and important type of coastal wetlands in the tropical and subtropical zones worldwide. The abundance and spatial distribution of microplastics in the mangrove sediments however are still poorly understood. The present study aimed to illustrate the characteristics, abundance and spatial distribution of microplastics in different mangrove sediments along the south-eastern coastal zones of China. Microplastic samples (roughly 10-20 kg fresh sediments at each site) taken from 21 sampling sites showed various shapes, colors, composition, sizes, surface morphology, abundance and strong spatial heterogeneity. Five different shapes of microplastics with a variety of colors were detected in the mangrove sediments, among which foams (74.6\%) and fibers (14.0\%) were the dominant types. The polymer composition of the microplastics identified based on the FT-IR and $\mu$-FTIR covered polystyrene (75.2\%), polypropylene (11.7\%), rayon (4.6\%), polyester (3.4\%), polyethylene (2.8\%) and acrylic (2.4\%). The observed microplastics with a size range of less than $2 \mathrm{~mm}$ made up $58.6 \%$ of the total microplastic particles. The microplastics had various surface morphologies, exhibiting complicated weathered surfaces. The abundance of microplastics showed a substantial variation among the sampling sites, ranging from 8.3 to 5738.3 items $\mathrm{kg}^{-1}$ (dry sediment). Altogether, our study provides a better understanding of microplastic pollution status and prevention policy-making of mangrove habitats in China.
\end{abstract}

(C) 2019 Elsevier B.V. All rights reserved.

\footnotetext{
* Corresponding author.

E-mail address: ymluo@yic.ac.cn (Y. Luo).
} 


\section{Introduction}

Microplastic pollution is of increasing concern in all habitats worldwide, especially in coastal environments including water column (Cole et al., 2011; Isobe et al., 2014), beaches (Browne et al., 2011; Young and Elliott, 2016; Lots et al., 2017), estuaries (Yonkos et al., 2014; Zhao et al., 2015; Lebreton et al., 2017), mariculture areas (Chen et al., 2018; Zhu et al., 2019) and fishing ports (Aytan et al., 2016; Zhou et al., 2018). However, less attention has been paid to microplastic pollution in the coastal wetland sediments worldwide. Mangroves are a unique type of coastal wetlands, which plays an important role in ecosystem services such as food and water provisioning, nutrient cycling, environment purifying, carbon sequestering and climate regulation, as well as cultural services (Giri et al., 2008; Mcleod et al., 2011). Mangroves are mainly distributed in the inter-tidal zone of the tropical and subtropical regions, constituting a total area of $81,485 \mathrm{~km}^{2}$ in 2014 (Hamilton and Casey, 2016) with $42 \%$ of mangroves being located in Asia (Giri et al., 2011). Until recently, only a few studies are available focusing on microplastic pollution in mangrove sediments. Nor and Obbard (2014) firstly investigated the occurrence of microplastics in seven inter-tidal mangrove habitats in Singapore. In their study, the average abundance of microplastics from 7 mangrove sites varied from 12.0 to 62.7 items $\mathrm{kg}^{-1}$, and the majority of microplastics were fibers with the size of less than $20 \mu \mathrm{m}$. Four polymer types, including polyethylene (PE), polypropylene (PP), nylon and polyvinyl chloride, were identified as the dominant microplastics (Nor and Obbard, 2014). Despite the numerous investigations on microplastic pollution in sediments, seawaters and estuaries along China's coast (Yu et al., 2016; Dai et al., 2018; Zhou et al., 2018; Mai et al., 2018; Peng et al., 2017; Zhu et al., 2019; Tsang et al., 2017), studies focusing on the status of microplastic pollution in the mangrove sediments of China are scarce. The total mangrove area in China is $344.72 \mathrm{~km}^{2}$ (Dan et al., 2016), spanning over 5 provinces including Hainan, Guangxi, Guangdong, Fujian and Zhejiang, as well as Hong Kong and Taiwan. However, according to our knowledge, only two studies focusing on microplastic pollution in the coastal environment of Guangxi province examined the mangrove habitat, including the sediments and the surrounding seawater (Li et al., 2018; Zhu et al., 2019). The abundance of microplastics ranged from 1.2 to 12852.0 items $\mathrm{kg}^{-1}$ with fragments and fibers dominating. PE, $\mathrm{PP}$, rayon and polyester were the main polymers (Li et al., 2018; Zhu et al., 2019).

The abundance, distribution and retention features of microplastics in mangrove sediments are affected by both natural factors (i.e., water hydrodynamics, mangrove height and density, sediment grain size.) and human activities (mariculture, tourism and coastal dumping) (do Sul et al., 2014; Lima et al., 2016), but the specific mechanism and their particular effects remain unclear.

The aims of this study are (1) to illustrate the characteristics, abundance and spatial distribution of microplastics in different mangrove sediments covering the main mangrove forest growing areas of China, and (2) to explore the potential sources, influencing factors and their relationship to the distribution and retention of microplastics in the mangrove sediments. Results of this study can provide important data on the processes influencing microplastic distribution in mangroves. They might also be helpful to local authorities setting up microplastic pollution prevention measures and developing conservation policy for the mangrove area of China.

\section{Materials and methods}

\subsection{Sites description and sample collection}

Sediments samples were collected from 21 sampling sites from different mangrove wetlands located along the $12,000 \mathrm{~km}$ coast- line in the southeast of China. The samples from Guangxi and Hainan provinces were collected in November 2015, and the rest of samples were collected from April to June 2017. The sampling sites covered five provinces from the south of the tropical zone (Hainan province) to the north of mid-subtropical zone (Zhejiang province) (Table 1). The sampling sites were highly diverse and showed different levels of utilization like mariculture areas, harbors, tourism areas, nature reserves, estuaries. In this study also five beaches without mangrove vegetation (see Table 1 and Table $\mathrm{S} 1$ for detailed descriptions) were included. The five beaches were selected based on similar geographical and utilization conditions to and near corresponding mangrove areas for further comparison of microplastic abundances.

The sampling method followed the description in Zhou et al. (2018). Briefly, every sample from each site was taken randomly using a multipoint mixed method. One square was chosen randomly for sampling and then 5-7 squares were chosen every $20 \mathrm{~m}$ interval along the S-shaped route. The sediments were sampled from each $30 \times 30 \mathrm{~cm}^{2}$ square by taking roughly the top $2 \mathrm{~cm}$ of the sediments using a clean stainless-steel shovel. Then the sediment samples from the squares were mixed together in a sampling bag and homogenized in home laboratory without crosscontamination. The water contents of the sediment samples were determined after drying in an oven at $105^{\circ} \mathrm{C}$ for $12 \mathrm{~h}$ to a constant weight.

Table 1

Locations, areas and sediment textures of the sampling sites located in Chinese coastal mangrove wetlands and non-mangrove beaches.

\begin{tabular}{|c|c|c|c|}
\hline Sites & Locations & $\begin{array}{l}\text { Mangrove areas } \\
\left(\mathrm{km}^{2}\right) / \text { city }\end{array}$ & $\begin{array}{l}\text { Sediment } \\
\text { texture }\end{array}$ \\
\hline HN1 ${ }^{\mathrm{a}}$ & Haikou, Hainan & 17.97 & Muddy \\
\hline HN2 & Sanya, Hainan & 2.41 & Muddy \\
\hline$G X 1^{b}, G X 2, G X 3$ & $\begin{array}{l}\text { Fangchenggang, } \\
\text { Guangxi }\end{array}$ & 21.38 & $\begin{array}{l}\text { Muddy; } \\
\text { Sandy }\end{array}$ \\
\hline GX4 & Qinzhou, Guangxi & 36.03 & Sandy \\
\hline $\begin{array}{l}\text { GX5, GX6, GX7, } \\
\quad \text { GX8 }\end{array}$ & Beihai, Guangxi & 30.39 & $\begin{array}{l}\text { Muddy; } \\
\text { Sandy }\end{array}$ \\
\hline GD1 & $\begin{array}{l}\text { Zhanjiang, } \\
\text { Guangdong }\end{array}$ & 142.74 & Muddy \\
\hline GD2 & $\begin{array}{l}\text { Maoming, } \\
\text { Guangdong }\end{array}$ & 2.55 & Muddy \\
\hline GD3 & $\begin{array}{l}\text { Yangjiang, } \\
\text { Guangdong }\end{array}$ & 13.26 & Muddy \\
\hline GD4 & $\begin{array}{l}\text { Jiangmen, } \\
\text { Guangdong }\end{array}$ & 12.29 & Muddy \\
\hline GD5 & $\begin{array}{l}\text { Zhuhai, } \\
\text { Guangdong }\end{array}$ & 10.16 & Muddy \\
\hline GD6 & $\begin{array}{l}\text { Shenzhen, } \\
\text { Guangdong }\end{array}$ & 1.76 & Muddy \\
\hline GD7 & $\begin{array}{l}\text { Shantou, } \\
\text { Guangdong }\end{array}$ & 5.59 & Muddy \\
\hline FJ1, FJ2 & Zhangzhou, Fujian & 6.56 & Muddy \\
\hline $\mathrm{FJ} 3$ & Quanzhou, Fujian & 2.98 & Muddy \\
\hline $\mathrm{ZJ} 1^{\mathrm{c}}$ & Wenzhou, Zhejiang & 0.09 & Muddy \\
\hline FCG $^{\mathrm{d}}$ & $\begin{array}{l}\text { Fangchenggang, } \\
\text { Guangxi }\end{array}$ & Non-mangrove & Sandy \\
\hline $\mathrm{QZ}^{\mathrm{d}}$ & Qinzhou, Guangxi & Non-mangrove & Sandy \\
\hline $\mathrm{BH}^{\mathrm{d}}$ & Beihai, Guangxi & Non-mangrove & Sandy \\
\hline $\mathrm{MM}^{\mathrm{d}}$ & $\begin{array}{l}\text { Maoming, } \\
\text { Guangdong }\end{array}$ & Non-mangrove & Sandy \\
\hline$W^{d}$ & Wenzhou, Zhejiang & Non-mangrove & Sandy \\
\hline
\end{tabular}

\footnotetext{
a Only two sites were accessible within Hainan province due to the strict entry permission by local management section.

b Two subsites with different heights and densities of mangrove forests were selected at GX1 site to compare the differences in microplastics abundance in the mangrove sediments.

c Only one sampling site was available in Zhejiang province due to the climate conditions for the growth of mangrove forest.

d The sites of FCG, QZ, BH, MM and WZ were sampled for comparison with their corresponding mangrove area.
} 


\subsection{Microplastics flotation}

Microplastics were isolated from the sediment samples by sequential flow separation and flotation apparatus as described by Zhang et al (2015) and Zhou et al (2018). Briefly, $0.5 \mathrm{~kg}$ fresh sediment was transferred to a sample cup, which was placed inside a $10 \mathrm{~L}$ container. Saturated sodium chloride solution $\left(1.2 \mathrm{~g} \mathrm{~cm}^{-3}\right)$ was pumped into the sample cup at a flow rate of $1.0 \mathrm{~L} \mathrm{~min}^{-1}$, and air was transferred to the sample cup simultaneously at a rate of $0.05 \mathrm{~L} \mathrm{~s}^{-1}$ using bubble stones. This way low-density material including microplastics was overflowed with the solution into the outside container. All the suspension in the outside container was then pumped into a stainless steel sieve with a pore diameter of $50 \mu \mathrm{m}$ after overflowing finished. The procedure was repeated three times. Then the suspected plastic particles visible to the naked eye (usually larger than $2 \mathrm{~mm}$ ) were picked out from the residues with stainless steel tweezers and stored in petri dishes. The rest of residues on the sieve were collected and settled in a sodium iodide solution $\left(1.6 \mathrm{~g} \mathrm{~cm}^{-3}\right)$ for $24 \mathrm{~h}$ for further microplastics separation. The floating particles were filtered using a nitrocellulose filter with a pore diameter of $5 \mu \mathrm{m}$ (Whatman AE 98, Germany).

\subsection{Microplastics observation and counting}

The observation of particles were executed with a stereomicroscope $(6.1 \times \sim 55 \times$, S9I, Leica Corporation, Germany) equipped with CCD camera. Then, all the observed microplastics were classified and counted by dividing them according to different shapes, colors and sizes. The abundance of microplastics is presented as the number of microplastics per $\mathrm{kg}$ dry sediment (items $\mathrm{kg}^{-1}$ ).

\subsection{Polymer identification and morphologies analysis}

The plastic particles with the size above $2 \mathrm{~mm}$ were selected for polymer identification using a Fourier Transform Infrared Spectrometer (FTIR, Nicolet iS5, Thermo Company, USA) equipped with an iD7 ATR accessory and diamond crystal on a single reflection plate. The FTIR were run at a mid-IR range of $650-4000 \mathrm{~cm}^{-1}$ and a resolution of $4 \mathrm{~cm}^{-1}$ at a rate of 32 scans. The particles with size below $2 \mathrm{~mm}$ and all the fibers were identified using a $\mu$-FTIR spectrometer (Nicolet iN10, Thermo Scientific, USA) with its spectral region $650-4000 \mathrm{~cm}^{-1}$ and resolution $8 \mathrm{~cm}^{-1}$ at a rate of 16 scans per analysis. All spectra were compared and identification was verified using the database (Hummel Polymer Sample Library, HR Polymer Additives and Plasticizers, HR Hummel Polymers and Additives, Synthetic Fibers by Microscope).

The surface morphology of microplastics was analyzed using a Field Emission Scanning Electron Microscope (SEM, Hitachi S4800) equipped with an EX-350 Energy Dispersive X-ray Microanalyzer, HORIBA EMAX Energy (Hitachi, Tokyo, Japan). Samples were dried and coated with Pt using an Ion Sputter (Hitachi E1045 ) before analysis. The SEM was operated at $3.0 \mathrm{kV}$ electron accelerating voltage and images were obtained by secondary electrons to reach the high resolution.

\subsection{Quality assurance (QA) and quality control (QC)}

Separation, enumeration and identification of microplastics were conducted in a micro-particles laboratory without crosscontamination. Some preventive measures were taken in the laboratory before the processing of the sample, including covering instruments with aluminum foil immediately after cleaning. The glass bottles, beakers and petri dishes were dried in the oven and covered with aluminum foil before use. All the samples and items were covered to prevent contamination during flotation and filtra- tion. The operator wore the non-textile jumpsuit during the experiment. Procedural blanks were obtained in parallel with samples in the laboratory. In the blanks only fibers were enumerated and 2-4 fibers (mean value of 3 ) with blue and transparent color were found. Thus, quantification of fibers in the field samples with similar fibers was corrected by removing the counts of fibers found in the blanks.

\subsection{Data analysis}

Data analysis and mapping were performed using Microsoft Excel 2010 and OriginPro 8.0 (OriginLab Corporation, Northampton, MA). Mapping of the spatial distribution of microplastics was carried out using ArcGIS 10.2 (ESRI, Redlands, CA).

\section{Results and discussion}

\subsection{Characteristics of microplastics in the mangrove sediments}

Different shapes of microplastics including foams, fibers, films, fragments and pellets were found in the mangrove sediments, of which foams, fibers and fragments were the most frequent (Fig. 1). The contribution of different microplastics shapes (Fig. 2) differ between the sampling sites mainly caused by exposition to different pollution sources. High numbers of foams were found in the sediments samples from Guangxi province, as foamed materials (such as floating frames, foamed fishing gear and foamed containers) are popularly used in the local mariculture. These foamed materials are easily broken into foam microplastics by photooxidation and mechanical abrasion (Song et al., 2017). Fibers were mainly detected in the sediments near the river estuaries, bays, harbors or tourism areas within the Guangdong and Fujian provinces. Here the delivery of terrestrial material by the rivers and the nearshore discharge formed the observed pattern (Browne et al., 2011; Zhao et al., 2015; Hernandez et al., 2017). Films and fragments were widely detected in almost all the sampling sites due to their complex anthropogenic sources. In contrast, pellets were rarely detected, only at two sampling sites GX1 and GD5, most likely originating from accidental leaking (Zhou et al., 2015; Zhou et al., 2018; Redford et al., 1997). All the detected microplastics showed a variety of colors including white, blue, black, red, yellow, green, purple and gray, some were transparent. Fibers were the most colorful among all the detected microplastics (Fig. S1-a). The dominant colors of fibers found in this study were blue $(34.7 \%)$ and transparent $(27.8 \%)$, which were also commonly detected elsewhere (Peng et al., 2017). Most of the fragments were transparent (38.5\%), green $(23.1 \%$ ) and blue (19.2\%), while foams and films were mainly comprised of white and transparent particles. These colored microplastics are probably easily taken up by many organisms mistaken as food resources (Nor and Obbard, 2014; TSetälä et al., 2018; Li et al., 2016), thus causing starvation to death, and the loss of biodiversity in mangrove habitat (Lusher et al., 2017).

The detected microplastics (Fig. 3b) were mainly composed of polystyrene (75.2\%), polypropylene (11.7\%), rayon $(4.6 \%)$, polyester (3.4\%), polyethylene (2.8\%) and acrylic (2.4\%). The diversity of the recognized polymers in this study was higher than the one reported from mangrove sediments in Singapore (Nor and Obbard, 2014) and from coastal sediments along the Bohai Sea and Yellow Sea, China (Zhou et al., 2018). FTIR confirmed all the foams were expanded PS (100\%), while the fragments and pellets were mainly composed of PP and PE (fragments: $81.8 \%$ PP and 18.2\%; pellets: $100 \% \mathrm{PP}$ ). The films were made up from PE (40.0\%), PP (40.0\%) and PS (20.0\%). The fibers consisted of various polymers, among those $43.1 \%$ were identified as purely synthetic 

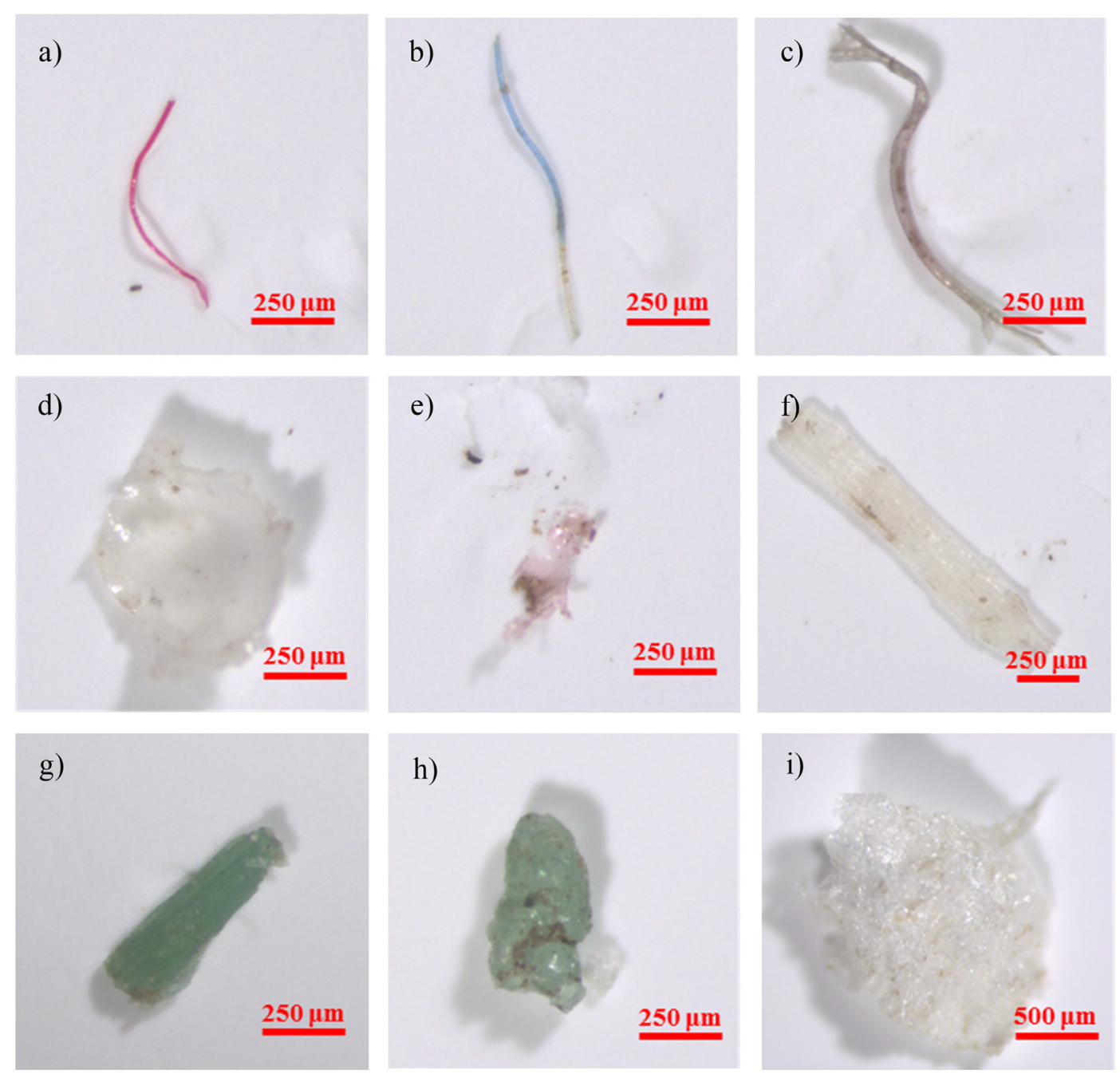

h)

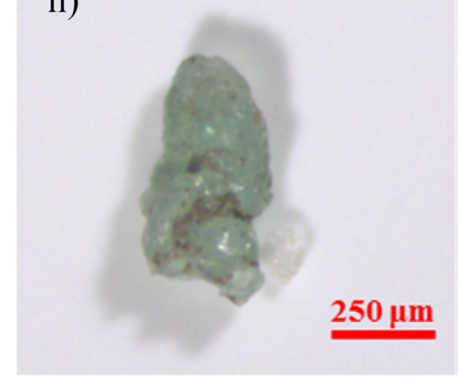

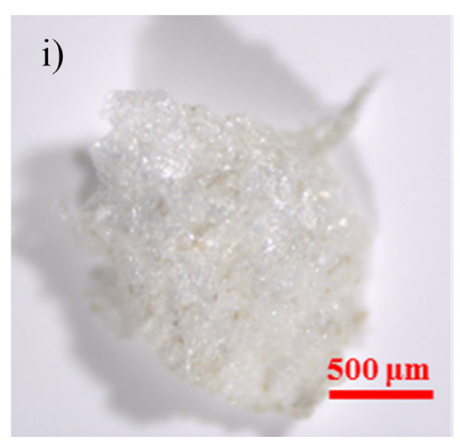

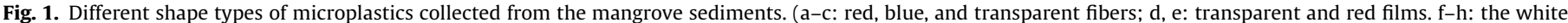

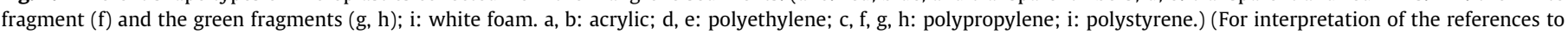
color in this figure legend, the reader is referred to the web version of this article.)

fibers, mainly PP (16.7\%), followed by polyester (15.3\%), and acrylic-based polymers (11.1\%). About $20.8 \%$ of the total fibers were rayon, which originated from natural polymer. In addition, about one third of the fibers $(36.1 \%)$ were cotton or plants fragments, which were not plastic components (Fig. S1-b). The great variety of polymers within the fibers was clearly related to their multiple sources, defragmentation of parent material and terrestrial inputs (Cincinelli et al., 2017; Murphy et al., 2016). PP and PS made up most of the microplastics identified in this study, mainly due to three reasons. Firstly, plastic products made from PP and PS are widely used in modern societies, and are popular in fishery and mariculture (Chowdhury et al., 2017; Poeta et al., 2017). Secondly, PP products and the floating expanded PS are prone to abrasion and fragmentation into pieces under the influence of ultraviolet radiation, mechanical stress due to wave and currents action, prevailing environmental conditions (e.g. salinity, temperature) and biological activity via biofilm formation, aggregation etc. (Carneiro et al., 2018; Weinstein et al., 2016; Ter Halle et al., 2016; Kwon et al., 2015). Lastly, the PE with low specific density and the floating ability of expanded PS allow them easily to be transported by tides, waves, currents or rivers. Consequently, these two polymers accumulate in coastal waters and sediments (Zhou et al., 2018) and are frequently identified in mangrove sediments (Nor and Obbard, 2014; Li et al., 2018).
The size of all the microplastics ranged from 0.05 to $5 \mathrm{~mm}$. Fig. 3a shows the spectrum of the size distribution of microplastics including large plastics $(5-15 \mathrm{~mm})$ enumerated in this study. In general, the highest abundance of microplastics occurred in the size range of $1-2 \mathrm{~mm}$, accounting for $46 \%$. In our study the most dominant particles were larger compared to the mangrove sediments from Singapore. Those were dominated by the size range smaller than $40 \mu \mathrm{m}$ and accounted for 58\%. This difference is most likely related to the smaller pore size $(1.6 \mu \mathrm{m})$ of the used filters (Nor and Obbard, 2014). The majority of fibers in this study comprised of particles with a size of less than $1 \mathrm{~mm}$ (57.1\%). Therein, fibers with a size range of $0.5-1 \mathrm{~mm}$ were the most abundant (36.3\%). The fraction contributed by foams, films and fragments with the size range of $1-2 \mathrm{~mm}$ were the highest in their size distributions (foams, 48.7\%; films, 28.6\%; fragments, $25.0 \%$, respectively). All the pellets in this study fell into the size range of $4-5 \mathrm{~mm}$, typical for manufactured plastic pellets used as raw materials for different plastic products (Takada et al., 2005).

The surface micro-morphologies of the microplastics from the mangrove sediments were additionally observed by SEM (Fig. 4a-e). All the tested samples exhibited complicated weathered surfaces. Foams and films had a rough surface with creases, concave and convex structures (Fig. 4a, c, e). The surface of the 


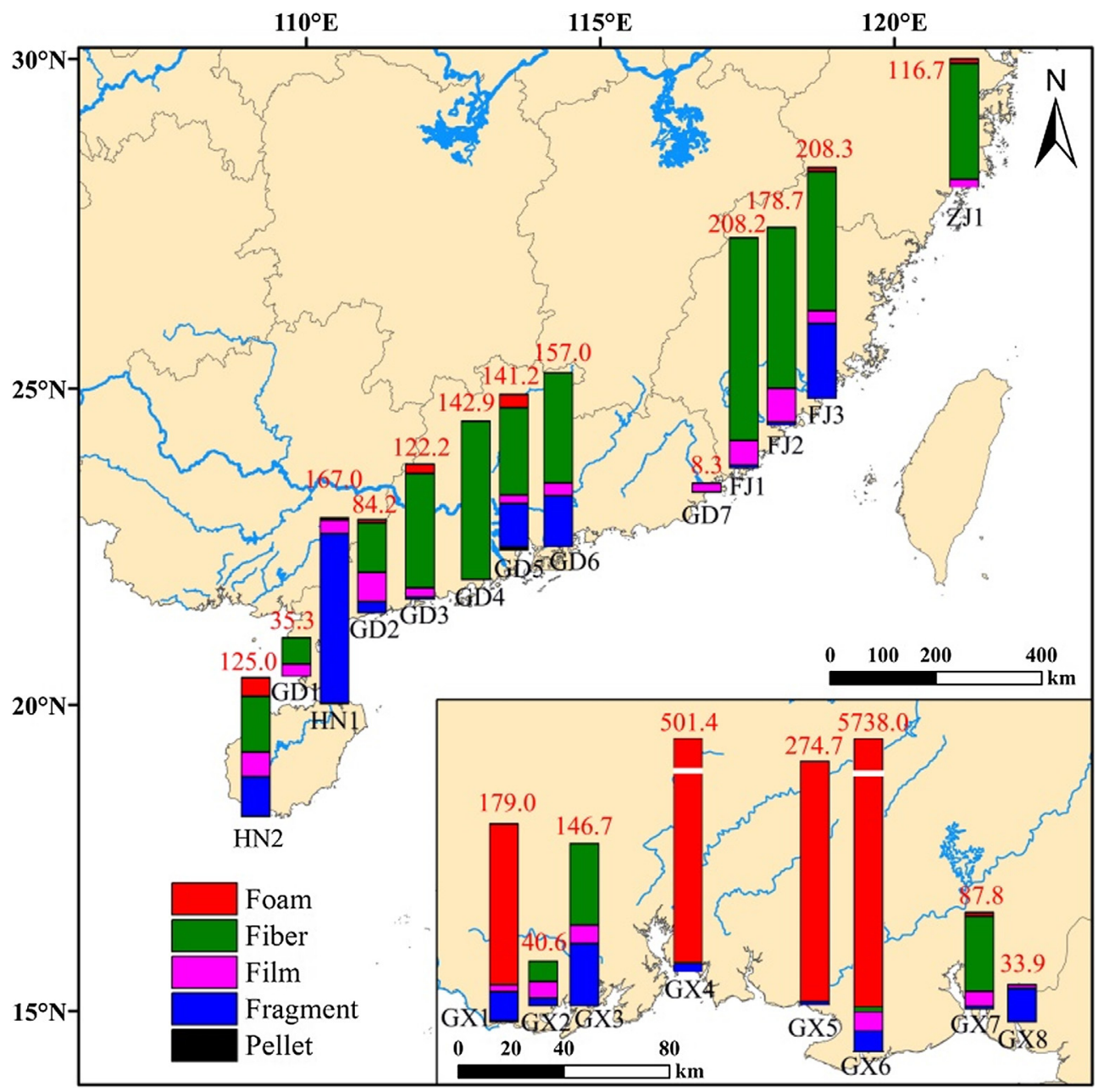

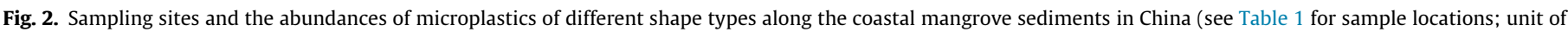
microplastics abundance: items $\mathrm{kg}^{-1}$ ).
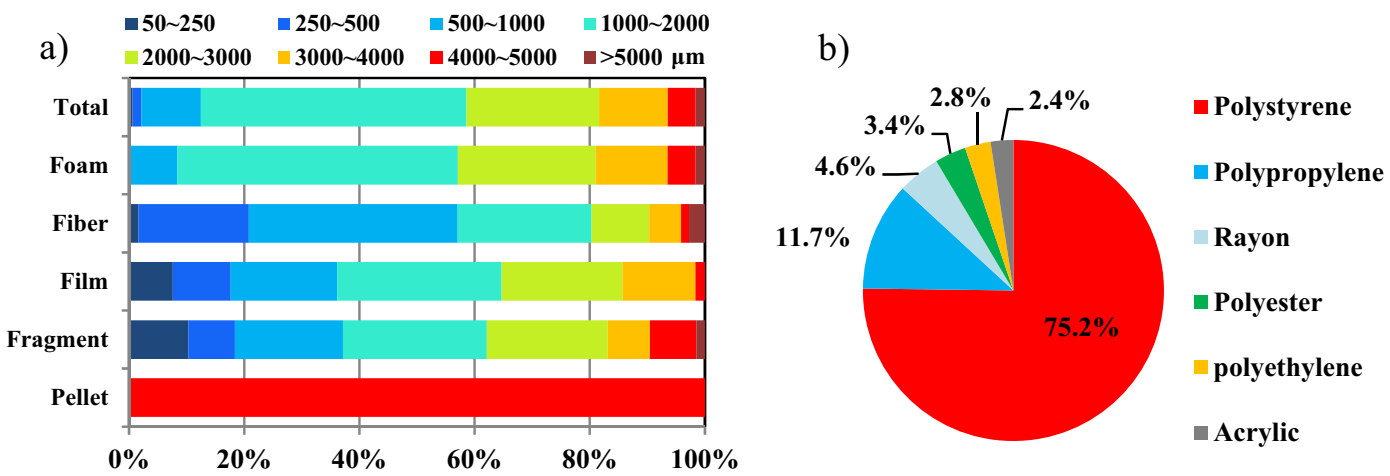

Fig. 3. Abundance (\%) of the extracted microplastics in the mangrove sediments according to size fractions (a) and polymers (b).

fibers and fragments had more cracks and scratches than creases (Fig. 4b, d). Interestingly, the surface morphologies of the fragments varied with sampling site. Fragments collected from the site GX1 in Guangxi province, showed more complicated characteristics than those from the site FJ3 in Fujian province (Fig. $4 \mathrm{f}-\mathrm{h}$ ). The former exhibited a rougher and more fragmented surface with creases, an indication of biofouling and particles adhering (Fig. 4f), while the latter showed some cracks but few creases and little attached materials (Fig. 4g). This probably is related to the differences of the prevailing hydrographic and weather conditions (such as stronger or longer UV exposure at the site GX1) between both geographical locations (Song et al., 2017; Kowalski et al., 2016). Furthermore, fragments from the sandy beach sediments without mangrove showed more severe fragmentation and more creases in comparison to fragments from the mangrove sediments (Fig. $4 \mathrm{~g}, \mathrm{~h}$ ). This is most likely because of the great ultraviolet radiation exposure and oxidation on the mangrove free beaches (Song et al., 2017). In addition, some fine particles on the surface of foams and a large number of clay mineral particles on the surface of the fragments were also observed (Fig. $4 \mathrm{i}-\mathrm{k}$ ). 

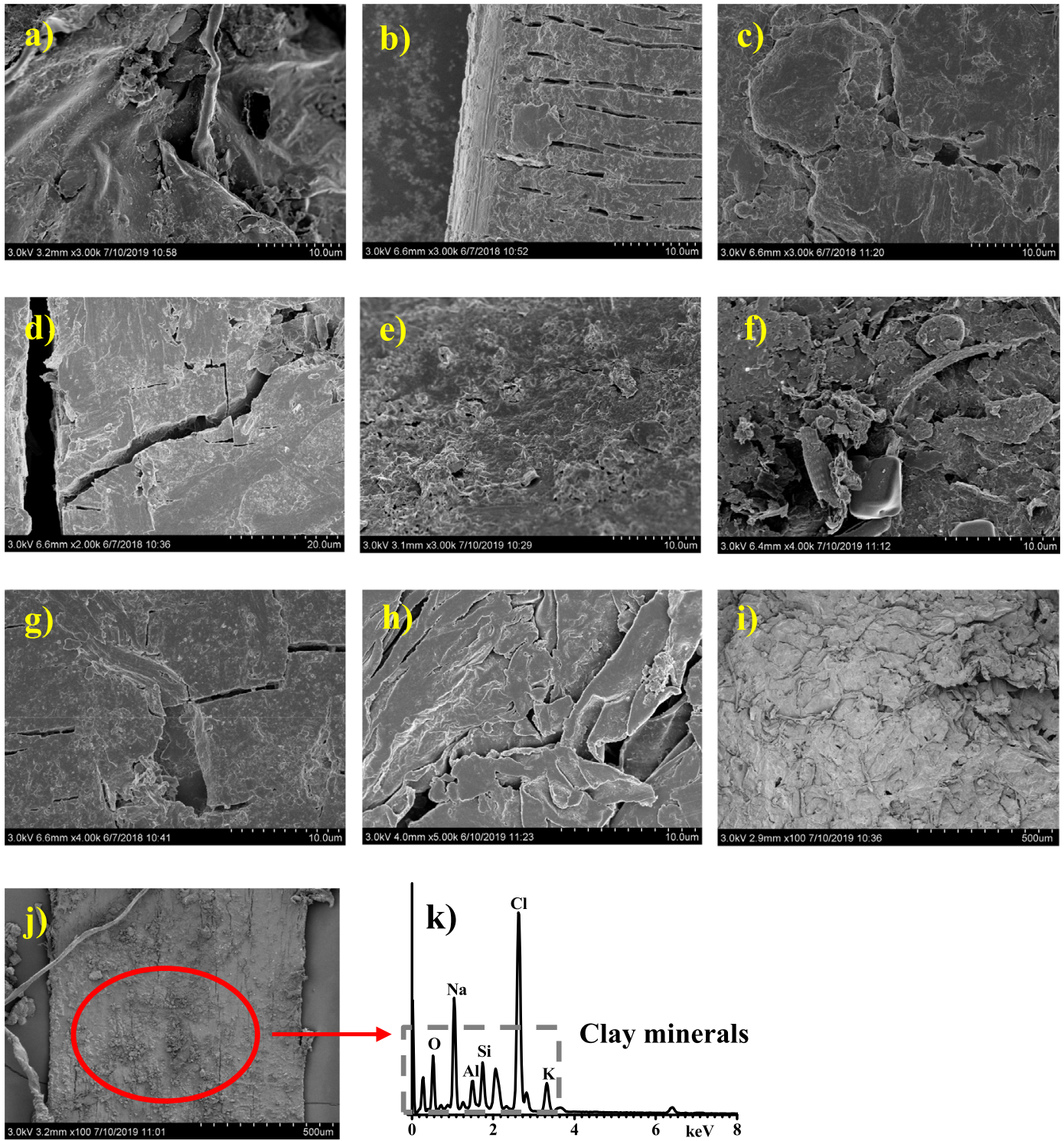

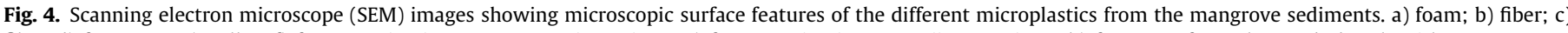

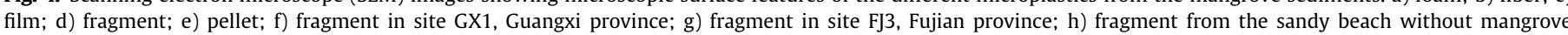

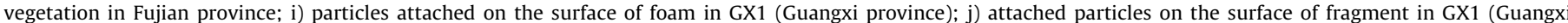
province); k) energy spectrum of particles attached to a fragment in $\mathrm{j}$ ) with associated elements.

\subsection{Abundance and spatial distribution of microplastics in the mangrove sediments}

In this study microplastics were detected in the mangrove sediments collected at all the sampling sites, but their abundances and spatial distribution showed substantial heterogeneity (Fig. 2). The microplastic abundance ranged from 8.3 to 5738.3 items $\mathrm{kg}^{-1}$. The highest abundance was detected at the site GX6, a highly touristic area and close to a mariculture area, while the lowest was found at the site GD7 in a mangrove nature reserve. Our study also showed a decline in the abundance of microplastics from one province to another province in the order from Guangxi (mean value, 875.3 items $\mathrm{kg}^{-1}$ ), Fujian (198.4 items $\mathrm{kg}^{-1}$ ), Hainan (146.0 items $\mathrm{kg}^{-1}$ ), Zhejiang (116.7 items $\mathrm{kg}^{-1}$ ) to Guangdong (98.7 items $\mathrm{kg}^{-1}$ ). It confirms a ubiquitous distribution of microplastics in the coastal mangrove sediments, with the distribution of microplastics closely related to the local utilization and discharge activities rather than the climate zones. In general, the microplastics detected in this study (mean value is 414.1 items $\mathrm{kg}^{-1}$ with a range from 8.3 to 5738.3 items kg${ }^{-1}$ ) exhibited a higher abundance and stronger spatial heterogeneity than the mangrove sediments from Singapore (mean value is 36.8 items $\mathrm{kg}^{-1}$ with a range from 12.0 to 62.7 items $\mathrm{kg}^{-1}$ ) (Nor and Obbard, 2014).

Additionally, even within a single province, the abundance distribution of microplastics was spatially heterogeneous. In the Guangxi province e.g., the microplastic abundance ranged from 33.9 to 5738.0 items $\mathrm{kg}^{-1}$. The highest abundance was found at the site GX6. In comparison the two sites located near the estuary showed lower microplastic abundances, at the sites GX5 (274.7 items $\mathrm{kg}^{-1}$ ) and GX1 (179.0 items $\mathrm{kg}^{-1}$ ). Microplastic abundance at the Yingluo National Mangrove Reserve (GX8) was the lowest (33.9 items $\mathrm{kg}^{-1}$ ), an obvious benefit from the strict environmental protection policies.

The accumulation and distribution of microplastics in the mangrove sediments are mainly affected by the following factors: 1) Intense human activities. In this study, high abundance of 


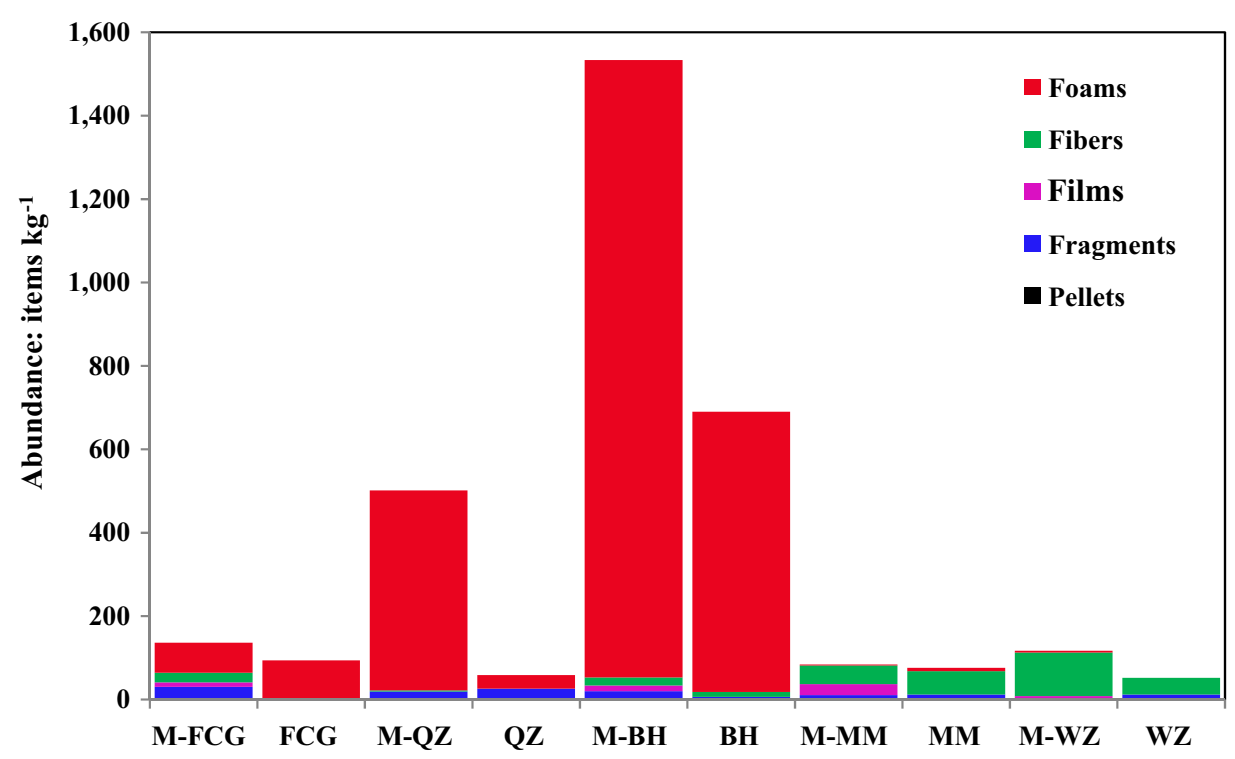

Fig. 5. Comparison of microplastics abundance between the coastal mangrove sediments and beach sediments without mangrove vegetation. M stands for Mangrove.

microplastics was found in the Guangxi province with a higherintensity of human activities such as mariculture, fishery, tourism and local direct dumping (Zang et al., 2019). Offshore oyster mariculture in Qinzhou Bay (Guangxi) was identified as the dominated source of foam (Zhou et al., 2016; Li et al., 2018). 2) Height and density of mangrove forest. Compared with the results from 5 nonmangrove beach sediments, the abundance of microplastics detected in the mangrove sediments was 1.1-8.5 times higher (Fig. 5). Furthermore, the distribution of microplastics in the mangrove sediments probably was influenced by the height and density of mangrove forest. Results from two separated subsites of GX1 (Fig. S2) showed that, microplastic abundance from the subsite with a higher density of mangrove trees $\left(0.5\right.$ trees $\left.\mathrm{m}^{-2}\right)$ and their height (around $2.0 \mathrm{~m}$ ) was significantly higher than the one from a less dense $\left(0.25\right.$ trees $\left.\mathrm{m}^{-2}\right)$ and lower (around $1.0 \mathrm{~m}$ ) vegetation subsite ( 309.0 vs 49.0 items $\mathrm{kg}^{-1}$ ). This agrees with results reported by do Sul et al. (2014) and Martin et al. (2019). 3) Sediment texture. In this study, microplastics from sandy sediments (GX1, GX4, GX5 and GX6) were dominated by foams ( $>90 \%$ ), while microplastics from muddy sediments were dominated by fibers and fragments (40 91\%) (Fig. S3). This indicates that, in addition to the factor of source difference, the sediment texture may influence the type of predominantly accumulated microplastics. This is consistent with our previous studies conducted in the norther coastal sediments of China (Zhou, 2016; Zhou et al., 2018). The result could also explain the clay minerals attached to the surface of the fragments in the muddy sediments as detected by SEM-EDS (Fig. 3k).

\section{Conclusions}

Mangroves play a crucial role in retention of microplastics from both marine and terrestrial inputs. Investigation of microplastics in the mangrove sediments collected from 21 sites covering the southeast coast of China showed a strong heterogeneity in the shapes, colors, sizes, surface morphologies, abundances and spatial distribution. As the main driving factors for the heterogeneity, the high-intensity of human activities, height and density of mangrove forest, as well as the sediment texture were identified. However, additional research is needed to assess the impact of microplastic pollution on mangrove wetland health and functioning at the ecosystem level.

\section{Declaration of Competing Interest}

The authors declare that they have no known competing financial interests or personal relationships that could have appeared to influence the work reported in this paper.

\section{Acknowledgements}

This work was funded by the National Key Research and Development Program of China, China (2016YFC1402202), the Key Research Program of Frontier Sciences, CAS, China (No. QYZDJSSW-DQC015), the Sino-German Cooperation Project "Megacity's fingerprint in Chinese southern marginal seas: Investigation of pollutant fingerprints and dispersal", MEGAPOL Project, German (BMBF, No. 03F0786A), and the National Natural Science Foundation of China, China (41771351). We thank Professor Huahong Shi at State Key Laboratory of Estuarine and Coastal Research, East China Normal University, China, for the help in the microplastics sample identification.

\section{Appendix A. Supplementary data}

Supplementary data to this article can be found online at https://doi.org/10.1016/j.scitotenv.2019.134807.

\section{References}

Aytan, U., Valente, A., Senturk, Y., Usta, R., Sahin, F.B.E., Mazlum, R.E., Agirbas, E., 2016. First evaluation of neustonic microplastics in Black Sea waters. Mar. Environ. Res. 119, 22-30.

Browne, M.A., Crump, P., Niven, S.J., Teuten, E., Tonkin, A., Galloway, T., Thompson, R., 2011. Accumulation of microplastic on shorelines worldwide: sources and sinks. Environ. Sci. Technol. 45 (21), 9175-9179.

Carneiro, J.R., Morais, M., de Lurdes Lopes, M., 2018. Degradation of polypropylene geotextiles with different chemical stabilizations in marine environments, Constr. Build. Mater. 165, 877-886.

Chen, M., Jin, M., Tao, P., Wang, Z., Xie, W., Yu, X., Wang, K., 2018. Assessment of microplastics derived from mariculture in Xiangshan Bay, China. Environ. Pollut. 242, 1146-1156.

Chowdhury, M.J., Nasrin, S., Al Faruque, M.A., 2017. Significance of agro-textiles and future prospects in Bangladesh. Eur. Sci. J. 13 (21), 139.

Cincinelli, A., Scopetani, C., Chelazzi, D., Lombardini, E., Martellini, T., Katsoyiannis, A., Fossi, M.C., Corsolini, S., 2017. Microplastic in the surface waters of the Ross Sea (Antarctica): occurrence, distribution and characterization by FTIR. Chemosphere 175, 391-400. 
Cole, M., Lindeque, P., Halsband, C., Galloway, T.S., 2011. Microplastics as contaminants in the marine environment: a review. Mar. Pollut. Bull. 62 (12), 2588-2597.

Dai, Z., Zhang, H., Zhou, Q., Tian, Y., Chen, T., Tu, C., Fu, C., Luo, Y., 2018. Occurrence of microplastics in the water column and sediment in an inland sea affected by intensive anthropogenic activities. Environ. Pollut. 242, 1557-1565.

Dan, X., Liao, B., Wu, Z., Wu, H., Bao, D., Dan, W., Liu, S., 2016. Resources, protection status and major threats of Chinese mangrove wetland (in Chinese). Ecol. Environ. Sci. 25 (7), 1237-1243.

do Sul, J.A.I., Costa, M.F., Silva-Cavalcanti, J.S., Araújo, M.C.B., 2014. Plastic debris retention and exportation by a mangrove forest patch. Mar. Pollut. Bull. 78(12), 252-257.

Giri, C., Ochieng, E., Tieszen, L.L., Zhu, Z., Singh, A., Loveland, T., Masek, J., Duke, N., 2011. Status and distribution of mangrove forests of the world using earth observation satellite data. Global Ecol. Biogeogr. 20 (1), 154-159.

Giri, C., Zhu, Z., Tieszen, L.L., Singh, A., Gillette, S., Kelmelis, J.A., 2008. Mangrove forest distributions and dynamics (1975-2005) of the tsunami-affected region of Asia. J. Biogeogr. 35 (3), 519-528.

Hamilton, S.E., Casey, D., 2016. Creation of a high spatio-temporal resolution global database of continuous mangrove forest cover for the 21st century (CGMFC-21). Global. Ecol. Biogeogr. 25 (6), 729-738.

Hernandez, E., Nowack, B., Mitrano, D.M., 2017. Polyester textiles as a source of microplastics from households: a mechanistic study to understand microfiber release during washing. Environ. Sci. Technol. 51 (12), 7036-7046.

Isobe, A., Kubo, K., Tamura, Y., Nakashima, E., Fujii, N., 2014. Selective transport of microplastics and mesoplastics by drifting in coastal waters. Mar. Pollut. Bull. 89 (1-2), 324-330.

Kowalski, N., Reichardt, A.M., Waniek, J.J., 2016. Sinking rates of microplastics and potential implications of their alteration by physical, biological, and chemical factors. Mar. Pollut. Bull. 109 (1), 310-319.

Kwon, B.G., Koizumi, K., Chung, S.Y., Kodera, Y., Kim, J.O., Saido, K., 2015. Global styrene oligomers monitoring as new chemical contamination from polystyrene plastic marine pollution. J. Hazard. Mater. 300, 359-367.

Lebreton, L.C., Van der Zwet, J., Damsteeg, J.W., Slat, B., Andrady, A., Reisser, J., 2017. River plastic emissions to the world's oceans. Nat. Commun. 8, 15611.

Li, J., Qu, X., Su, L., Zhang, W., Yang, D., Kolandhasamy, P., Li, D., Shi, H., 2016. Microplastics in mussels along the coastal waters of China. Environ. Pollut. 214, $177-184$.

Li, J., Zhang, H., Zhang, K., Yang, R., Li, R., Li, Y., 2018. Characterization, source, and retention of microplastic in sandy beaches and mangrove wetlands of the Qinzhou Bay, China. Mar. Pollut. Bull. 136, 401-406.

Lima, A.R.A., Barletta, M., Costa, M.F., Ramos, J.A.A., Dantas, D.V., Melo, P.A.M.C., Justio, A.K.S., Ferreira, G.V.B., 2016. Changes in the composition of ichthyoplankton assemblage and plastic debris in mangrove creeks relative to moon phases. J. Fish. Biol. 89 (1), 619-640.

Lots, F.A., Behrens, P., Vijver, M.G., Horton, A.A., Bosker, T., 2017. A large-scale investigation of microplastic contamination: abundance and characteristics of microplastics in European beach sediment. Mar. Pollut. Bull. 123 (1-2), 219-226.

Lusher, A., Hollman, P., Mendoza-Hill, J., 2017. Microplastics in fisheries and aquaculture: status of knowledge on their occurrence and implications for aquatic organisms and food safety. FAO Fisheries and Aquaculture Technical Paper. No. 615. Rome, Italy.

Mai, L., Bao, L.J., Shi, L., Liu, L.Y., Zeng, E.Y., 2018. Polycyclic aromatic hydrocarbons affiliated with microplastics in surface waters of Bohai and Huanghai Seas, China. Environ. Pollut. 241, 834-840.

Martin, C., Almahasheer, H., Duarte, C.M., 2019. Mangrove forests as traps for marine litter. Environ. Pollut. 247, 499-508.

Mcleod, E., Chmura, G.L., Bouillon, S., Salm, R., Björk, M., Duarte, C.M., Lovelock, C.E. Schlesinger, W.H., Silliman, B.R., 2011. A blueprint for blue carbon: toward an improved understanding of the role of vegetated coastal habitats in sequestering $\mathrm{CO}_{2}$. Front. Ecol. Environ. 9 (10), 552-560.

Murphy, F., Ewins, C., Carbonnier, F., Quinn, B., 2016. Wastewater treatment works (WwTW) as a source of microplastics in the aquatic environment. Environ. Sci. Technol. 50 (11), 5800-5808.
Nor, N.H.M., Obbard, J.P., 2014. Microplastics in Singapore's coastal mangrove ecosystems. Mar. Pollut. Bull. 79 (1-2), 278-283.

Peng, G., Zhu, B., Yang, D., Su, L., Shi, H., Li, D., 2017. Microplastics in sediments of the Changjiang Estuary, China. Environ. Pollut. 225, 283-290.

Poeta, G., Fanelli, G., Pietrelli, L., Acosta, A.T., Battisti, C., 2017. Plastisphere in action: evidence for an interaction between expanded polystyrene and dunal plants. Environ. Sci. Pollut. R. 24 (12), 11856-11859.

Redford, D.P., Trulli, H.K., Trulli, W.R., 1997. Sources of plastic pellets in the aquatic environment. In: Marine Debris. Springer, New York, NY, pp. 335-343.

Song, Y.K., Hong, S.H., Jang, M., Han, G.M., Jung, S.W., Shim, W.J., 2017. Combined effects of UV exposure duration and mechanical abrasion on microplastic fragmentation by polymer type. Environ. Sci. Technol. 51 (8), 4368-4376.

Takada, H., Mato, Y., Endo, S., Yamashita, R., Zakaria, M. P., 2005. Pellet Watch: global monitoring of persistent organic pollutants (POPs) using beached plastic resin pellets. In The Plastic Debris Rivers to Sea Conference: Focusing on the Land-Based Sources of Marine Debris, Redondo Beach, CA, USA.

Ter Halle, A., Ladirat, L., Gendre, X., Goudouneche, D., Pusineri, C., Routaboul, C. Tenailleau, C., Duployer, B., Perez, B., 2016. Understanding the fragmentation pattern of marine plastic debris. Environ. Sci. Technol. 50 (11), 5668-5675.

Tsang, Y.Y., Mak, C.W., Liebich, C., Lam, S.W., Sze, E.T., Chan, K.M., 2017. Microplastic pollution in the marine waters and sediments of Hong Kong. Mar. Pollut. Bull. 115 (1-2), 20-28.

TSetälä, O., Lehtiniemi, M., Coppock, R., Cole, M., 2018. Microplastics in Marine Food Webs, in: Zeng, E.Y. (Eds.), Microplastic contamination in aquatic environments. Elsevier Inc., pp. 339-363.

Weinstein, J.E., Crocker, B.K., Gray, A.D., 2016. From macroplastic to microplastic: degradation of high-density polyethylene, polypropylene, and polystyrene in a salt marsh habitat. Environ. Toxicol. Chem. 35 (7), 1632-1640.

Yonkos, L.T., Friedel, E.A., Perez-Reyes, A.C., Ghosal, S., Arthur, C.D., 2014 Microplastics in four estuarine rivers in the Chesapeake Bay. USA. Environ. Sci. Technol. 48 (24), 14195-14202.

Young, A.M., Elliott, J.A., 2016. Characterization of microplastic and mesoplastic debris in sediments from Kamilo Beach and Kahuku Beach, Hawai'i. Mar. Pollut. Bull. 113 (1-2), 477-482.

Yu, X., Peng, J., Wang, J., Wang, K., Bao, S., 2016. Occurrence of microplastics in the beach sand of the Chinese inner sea: the Bohai Sea. Environ. Pollut. 2016 (214), $722-730$.

Zang, Z., Zou, X., Song, Q., Yao, Y., 2019. Analysis of the spatiotemporal correlation between vegetation pattern and human activity intensity in Yancheng coastal wetland, China. Anthropocene Coasts 2 (1), 87-100.

Zhang, H., Zhou, Q., Luo, Y., Tu, C., Zhang, R., Li, Y., 2015. A method and apparatus of continuous flow and floating separation for microplastics. China Patent, Application Number: 201510227085.1.

Zhao, S., Zhu, L., Li, D., 2015. Microplastic in three urban estuaries, China. Environ. Pollut. 206, 597-604.

Zhou, Q., 2016. Occurrences and Ecological Risks of Microplastics in the Typical Coastal Beaches and Seas (in Chinese). Master's Thesis. Yantai Institute of Coastal Zone Research, Chinese Academy of Sciences, Yantai, pp. 34-52.

Zhou, Q., Zhang, H., Fu, C., Zhou, Y., Dai, Z., Li, Y., Tu, C., Luo, Y., 2018. The distribution and morphology of microplastics in coastal soils adjacent to the Bohai Sea and the Yellow Sea. Geoderma 322, 201-208.

Zhou, Q., Zhang, H., Li, Y., Luo, Y., 2015. Progress on microplastics pollution and its ecological effects in the coastal environment (in Chinese). Chinese. Sci. Bull. 60 (33), 3210-3220.

Zhou, S., Hou, X., Li, X., Wang, Y., Wang, L., Mu, Y., 2016. Characteristics and development strategies of oyster industry in Guangxi-in-depth interview survey based on farmers, enterprises, government administrations (in Chinese). Jiangsu Agric. Sci. 44 (1), 422-426.

Zhu, J., Zhang, Q., Li, Y., Tan, S., Kang, Z., Yu, X., Lan, W., Cai, L., Wang, J., Shi, H., 2019. Microplastic pollution in the Maowei Sea, a typical mariculture bay of China Sci. Total. Environ. 658, 62-68. 